\title{
A INTERAÇÃO DISCURSIVA EM ENUNCIADOS CONCRETOS EM CIRCULAÇÃO NO TWITTER
}

\section{THE DISCURSIVE INTERACTION IN CONCRETE PROPOSITIONS ON TWITTER}

\author{
Aloísio de Medeiros Dantas ${ }^{1}$ \\ Manassés Morais Xavier ${ }^{2}$ \\ Raniere Marques de Melo $^{3}$
}

\begin{abstract}
RESUMO: Este artigo investigou a inter-relação entre discurso e sociedade, tendo como escopo o olhar para processos de interações discursivas ocorridas em redes sociais digitais, especificamente, no Twitter. Para tanto, tem os estudos da Análise Dialógica do Discurso, do Círculo de Bakhtin, como fundamento teórico, sobretudo, os conceitos de enunciado concreto e de suas possíveis réplicas. Objetivou-se compreender a circulação de enunciados concretos em postagens e em comentários on line nas contas de duas pessoas públicas no Twitter, a saber: o ex-ministro da Educação, Abraham Weintraub, e a deputada federal pelo estado do Rio de Janeiro, Jandira Feghali. Nessas condições, trata-se de uma pesquisa netnográfica e o evento motivador que gerenciou a produção dos enunciados na rede ocorreu em 08/03/2021, quando o ministro do Supremo Tribunal Federal (STF), Edson Fachin, anulou as condenações ao ex-presidente Luiz Inácio Lula da Silva em relação à Operação Lava Jato. Do ponto de vista dos resultados, os dados analisados inserem as redes sociais como ecossistemas comunicativos que aguçam a circulação de discursos vários, reforçando a perspectiva do Círculo de Bakhtin que apregoa a necessidade de que a palavra e outras linguagens querem sempre ser ouvidas e, além desse movimento, querem sempre ser respondidas em um exercício dialógico de compreensões e de respostas a enunciados concretos.
\end{abstract}

PALAVRAS-CHAVE: Interações discursivas. Enunciado concreto. Redes sociais digitais. Twitter. Lula.

ABSTRACT: This article investigated the interrelationship between discourse and society, having the aim to look at processes of discursive interactions occurred on digital social networks, specifically on Twitter. For that, it has the studies of the Dialogical Discourse Analysis, of the Bakhtin Circle, as theoretical background, especially, the concepts of concrete proposition and possible responses. The objective was to understand the circulation of concrete propositions in posts and comments online in the accounts of two public people on Twitter, which are, the former Minister of Education, Abraham Weintraub, and the federal congressman from the state of Rio de Janeiro, Jandira Feghali. Under these conditions, this is a netnographic research and the motivating event that organized the production of the propositions in the network occurred on March, 8th, 2021, when the Minister of the Supreme Federal Court (SFC), Edson Fachin, annulled the convictions of the former President Luiz Inácio Lula da Silva in relation to Lava Jato Operation. From the point of view of the results, the analyzed data insert social networks as communicative ecosystems that stimulate the circulation of various speeches, reinforcing the perspective of the Bakhtin Circle that divulges the need of the word and other languages to be always heard and, in addition of this movement, they always want to be answered in a dialogical exercise of comprehension and responses to concrete propositions.

KEYWORDS: Discursive interactions. Concrete proposition. Digital social networks. Twitter. Lula.

\section{Introdução}

O presente artigo situa-se, teoricamente, no âmbito da Análise Dialógica do Discurso, advinda das contribuições do Círculo de Bakhtin. Esse lugar de incursão teórica concebe a

\footnotetext{
${ }^{1}$ Doutor em Linguística e Língua Portuguesa pela Universidade Estadual Paulista - Araraquara. Docente do Curso de Letras da Universidade Federal de Campina Grande. Endereço eletrônico: alodanta@yahoo.com.br. 2 Doutor em Linguística pela Universidade Federal da Paraíba. Docente do Curso de Letras da Universidade Federal de Campina Grande. Endereço eletrônico: manassesmxavier@yahoo.com.br.

${ }^{3}$ Doutorando e Mestre em Linguística pela Universidade Federal da Paraíba. Docente do Curso de Letras da Universidade Estadual da Paraíba. Endereço eletrônico: prof.ranieremarques@gmail.com.
} 
linguagem como orientada pelo social, como uma ponte lançada entre um eu e um outro. Portanto, lê as múltiplas vozes como um fenômeno inserido em um terreno interindividual sem o qual não seria possível se pensar a linguagem.

Dentro dessa linha de raciocínio, situamos as redes sociais digitais como espaços de interações discursivas que atraem a circulação de enunciados concretos fundamentados, justamente, em um terreno interindividual capaz de agregar diferentes vozes, diferentes pontos de vista sobre os acontecimentos que pautam a vida social.

Nesse sentido, elencamos como objetivo desse trabalho, oriundo de uma pesquisa netnográfica, compreender a circulação de enunciados concretos em postagens e em comentários on line nas contas de duas pessoas públicas na rede social Twitter, a saber: o exministro da Educação, Abraham Weintraub, e a deputada federal pelo estado do Rio de Janeiro, Jandira Feghali.

O evento motivador que gerenciou a produção dos enunciados na rede ocorreu em 08/03/2021, quando o ministro do Supremo Tribunal Federal (STF), Edson Fachin, anulou as condenações ao ex-presidente Luiz Inácio Lula da Silva em relação à Operação Lava Jato, considerando, portanto, que a $13^{\mathrm{a}}$ Vara Federal de Curitiba não tinha competência para julgar casos do triplex do Guarujá, do sítio de Atibaia e do Instituto Lula.

Oferecidos esses esclarecimentos, destacamos que o texto se organiza, para além dessa introdução, em uma discussão teórica sobre a noção de enunciado concreto e de réplicas a enunciados, bem como das redes sociais digitais enquanto ecossistemas comunicativos de interações discursivas; uma discussão metodológica e outra analítica, seguidas das considerações finais e das referências bibliográficas.

\section{A noção de enunciado concreto}

Ao defender a necessidade de compreender a unidade da comunicação, em atuação no discurso, Mikhail Bakhtin (2016) decide pensar uma delimitação clara entre a oração e o enunciado. Em seu aspecto efetivo de realização, a comunicação discursiva ocorre entre um falante (escritor) e um ouvinte (leitor), que utilizam, na potencialidade e conhecimento internalizado, sistemas linguísticos e, na produção contextualizada de falas e textos, gêneros discursivos. Esses domínios se concretizam por orações e enunciados. O linguista russo, então, defende o uso comunicativo dos enunciados, numa "compreensão ativamente responsiva real e plena, que se atualiza na subsequente resposta real e em voz alta" (BAKHTIN, 2016, p. 25). Neste tópico, trataremos do enunciado em ligação com outros enunciados, o que o tornará concreto na comunicação discursiva.

Entretanto, precisamos distinguir, com clareza, a distinção entre oração e enunciado. Mário Perini prefere definir oração como

[...] uma estrutura que tipicamente contém um verbo e muitas vezes um ou mais complementos (sujeito, objetos e/ou sintagmas preposicionados, adjetivos ou adverbiais). Além disso, a oração pode conter um ou mais adjuntos. (PERINI, 2010, p. 65).

Segundo Bakhtin, "os limites da oração enquanto unidade da língua nunca são determinados pela alternância de sujeitos do discurso [...] A oração é um pensamento relativamente acabado, correlacionado de forma imediata com outros pensamentos do mesmo falante no conjunto do seu enunciado; ao término da oração, o falante faz uma pausa para logo passar ao seu pensamento subsequente, que continua, completa e fundamenta o primeiro" (BAKHTIN, 2016, p. 31-32). 
Como podemos constatar, a oração, por se caracterizar por uma unidade do sistema linguístico, começa e termina no falante/escritor, sem ligação com o contexto comunicativo, nem com o que seu ouvinte/leitor pode responder. Caracteriza-se como uma realidade apenas da língua, em seu viés de conjunto de regras. Apenas quando a oração entra em contato com o contexto paralinguístico e as respostas dos outros adquire sua caracterização de enunciado.

Dessa forma, temos quatro dimensões hierárquicas da linguagem: em seu estrato mais inferior, como base, temos os recursos linguísticos - o sistema linguístico, que existe em potencialidade; nos contextos intermediários, temos a oração, que se prende à língua em sua virtualidade, e o enunciado, unidade que se prende ao discurso, manifestada concretamente em gêneros e assimila o contexto comunicativo extralinguístico; na parte superior, temos o contexto comunicativo discursivo, no interior do qual acontecem as efetivas interações de falante/escritor e ouvinte/leitor.

A Figura 01 apresenta as quatro dimensões hierárquicas da linguagem descritas no parágrafo anterior.

Figura 1: Dimensões hierárquicas da linguagem

\section{CONTEXTO COMUNICATIVO DISCURSIVO}

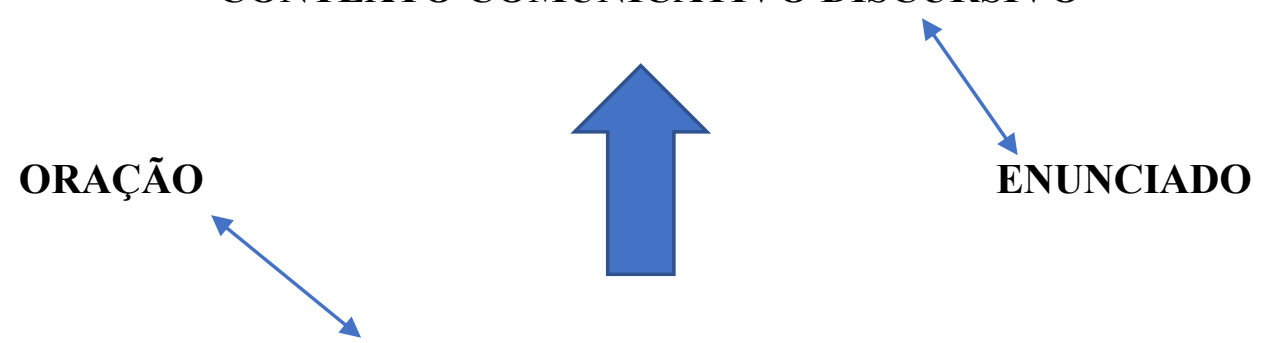

\section{SISTEMA LINGUÍSTICO}

Fonte: os autores.

Como afirma Bakhtin (2016, p. 33), "a oração enquanto unidade da língua tem natureza gramatical, fronteiras gramaticais, lei gramatical e unidade." Por outro lado, embora o enunciado possa se servir de orações, estas não se constituem em enunciados de uma comunicação discursiva, porque lhes falta a alternância de falante e ouvinte, as orações ficam presas na gramática da língua. Podemos concluir que o estudo de orações ou frases, sem a sua compreensão como enunciados concretos, não conduz a um estudo adequado da língua, porque lhe retira um aspecto central: os interlocutores, o contexto sócio-discursivo e as interações. Então, o que vem a ser enunciado concreto? É o que discutiremos em seguida, neste texto.

O enunciado concreto, sob a ótica de Souza (2002), se caracteriza por ser um fato real e uma unidade da comunicação verbal, com pausas reais; e por ter um acabamento real, irreproduzível, com autor e destinatário. É necessário um esforço dos participantes do discurso para a construção de um enunciado concreto, de modo que este abranja as orações linguísticas, ao mesmo tempo em que o pesquisador que procura o enunciado concreto vai encontrá-lo como discurso do outro, numa confluência de vozes: o eu e o tu; o eu e o nós; o $e u$, o tu, o nós e os outros. A dimensão eu x tu é a mais próxima da oração da língua; o eu x o nós já permite uma primeira interação discursiva; no entanto, é na dimensão o $e u$ x o $t u$ e o nós $\mathrm{x}$ os outros que a arquitetura da construção do enunciado concreto se faz completa, com irradiação para respostas variáveis e polêmicas.

Segundo o mesmo autor (SOUZA, 2002, p. 73), "pensar como unidade real, concreta, da comunicação verbal significa tomar os elementos dialógicos como fonte de uma 
compreensão ativa e científica", ou seja, a dimensão do $e u$ x tu, do nós x outros, o que demonstram as relações dialógicas. Essas relações dialógicas são extralinguísticas, mas também discursivas, com diferentes formas, permeadas de fatores sociais e orientadas para o discurso do outro. $\mathrm{O}$ enunciado concreto, portanto, se insere em contextos sociais - campo fértil de aspectos econômicos, culturais e político -, numa percepção formal distinta - os diferentes gêneros discursivos da esfera econômica, política, religiosa, estética, midiática -, e, por fim, uma concepção de sujeito que anula o EGO e dá predominância ao OUTREM. O enunciado concreto é uma realização de fraturas sociais, genéricas e com descentramento de sujeito.

Com essa perspectiva, Geraldo Souza (2002, p. 76) afirma:

O todo do enunciado concreto é o produto da interação entre falantes num determinado contexto e no interior de uma situação social complexa [...] $\mathrm{O}$ enunciado é dialógico, o discurso é dialógico, a comunicação é, também, dialógica. Nesse sentido, é importante salientar que todo o projeto de investigação dialógica do enunciado concreto é uma investigação dinâmica. Consequentemente, o seu conceito de comunicação difere daquele completamente pronto e estático, e segundo o Círculo, radicalmente incorreto - desenvolvido pelos formalistas nos anos 20.

Por essa perspectiva, o princípio dialógico está entranhado no próprio enunciado, porque este já traz em si a sociedade, o gênero discursivo e os outros sujeitos/sujeitos outros. Ninguém pode esquecer que um simples enunciado, como Preciso ir para casa implica numa sociedade que organiza a habitação em "casa", de um gênero discursivo injuntivo, no qual o sujeito introjeta seus deveres e obrigações, bem como que há outros sujeitos para quem dirige o enunciado, mas também sujeitos outros que o interpretam.

Sempre que o falante/escritor usa um enunciado concreto mobiliza esse quadro: os fatores sociais, em todos os seus aspectos; o gênero discursivo, em suas diferentes esferas; e os outros sujeitos e sujeitos outros, que dialogam responsivamente.

Souza (2002, p. 81-82) percebe o diálogo em três dimensões: o micro-diálogo, ou diálogo interior, interno ao enunciado, a do sujeito consigo mesmo; o diálogo exterior realizado numa determinada situação, pode ser a conversação ou diálogo entre duas ou mais pessoas; e o diálogo amplo, o grande e infinito diálogo, em que não há nem a primeira nem a última palavra, são "[...]as relações dialógicas entre os enunciados concretos, vivos." (SOUZA, 2002, p. 82). Esse último diálogo caracteriza o "diálogo inconcluso", que nos encaminha à noção de réplica ao enunciado, que será versado no subtópico seguinte.

\section{A noção de réplica ao enunciado}

A primeira observação que devemos fazer diz respeito às fronteiras do enunciado, no enquadre do contexto comunicativo discursivo. Quem especifica essa divisão e localização é a permutabilidade dos sujeitos do discurso. Todo enunciado envolve uma réplica, uma resposta, exigida ou dirigida ao outro. Vamos ilustrar, num quadro, alguns enunciados e suas consequentes réplicas: 
Volume 16 - Número 1 - jan/jul de 2021

Quadro 1 - Possibilidades de réplicas a enunciados concretos

\begin{tabular}{|c|c|c|c|c|}
\hline $\begin{array}{c}\text { CONTEXTO COMUNICATIVO } \\
\text { DISCURSIVO }\end{array}$ & ENUNCIADO & RÉPLICA & SUJEITO & OUTRO \\
\hline Diálogo cotidiano (face a face) & Monovocal & $\begin{array}{c}\text { Respostas } \\
\text { sucintas }\end{array}$ & Um só & Um só \\
\hline Conversação espontânea & Divisão de vozes & $\begin{array}{c}\text { Expectativa } \\
\text { de resposta }\end{array}$ & $\begin{array}{c}\text { Fala e cede } \\
\text { a fala }\end{array}$ & $\begin{array}{c}\text { Resposta } \\
\text { negociada com o } \\
\text { sujeito }\end{array}$ \\
\hline $\begin{array}{c}\text { Oralidade formal (palestras, } \\
\text { conferências, aula, sermão etc.) }\end{array}$ & $\begin{array}{c}\text { Princípio } \\
\text { dialógico }\end{array}$ & $\begin{array}{c}\text { Ato } \\
\text { responsivo }\end{array}$ & $\begin{array}{c}\text { Assume um } \\
\text { discurso }\end{array}$ & Debate \\
\hline $\begin{array}{c}\text { Escrita informal (aviso, bilhete, } \\
\text { anúncios etc.) }\end{array}$ & Monovocal & $\begin{array}{c}\text { Respostas } \\
\text { sucintas }\end{array}$ & Um só & Um só \\
\hline $\begin{array}{c}\text { Escrita formal (romance, tese de } \\
\text { doutorado, ensaio, poesias etc.) }\end{array}$ & $\begin{array}{c}\text { Princípio } \\
\text { dialógico }\end{array}$ & $\begin{array}{c}\text { Ato } \\
\text { responsivo }\end{array}$ & $\begin{array}{c}\text { Assume um } \\
\text { discurso }\end{array}$ & Polêmica \\
\hline $\begin{array}{c}\text { Enunciados digitais } \\
\text { (oralidade/escrita em redes sociais } \\
\text { digitais, vídeos, áudios, fotos, } \\
\text { memes, figurinhas) }\end{array}$ & Divisão de vozes & $\begin{array}{c}\text { Expectativa } \\
\text { de resposta }\end{array}$ & $\begin{array}{c}\text { Fala e cede } \\
\text { a fala }\end{array}$ & $\begin{array}{c}\text { Resposta } \\
\text { negociada com o } \\
\text { sujeito }\end{array}$ \\
\hline \begin{tabular}{c} 
Fonte: os autores. \\
\hline
\end{tabular}
\end{tabular}

Fonte: os autores.

Esse quadro mostra o quadro das réplicas aos enunciados. Segundo Bakhtin (2016, p. 30), as réplicas são relações entre enunciados de sujeitos diferentes, que pressupõem o outro. Para que o enunciado concreto realize em plenitude a réplica, três fatores devem ser interligados: a completude semântica-objetal do tema do enunciado; a intenção discursiva ou a vontade de produzir sentido, por parte do falante/autor; e a escolha de um gênero do discurso (BAKHTIN, 2016, p. 36-37).

No quadro, apresentamos diagramaticamente esses fatores. Verificamos que há dois grupos de intenções monovocais, nos quais as intenções discursivas são manter a unidade discursiva, com réplicas simples de um sujeito e um outro respondente, a escolha é pelo gênero do diálogo informal, dos avisos, bilhetes e anúncios; os temas desses enunciados giram em torno de situações simples do cotidiano. A conversão espontânea e os enunciados digitais são de fronteiras intermediárias entre os gêneros monovocais e os gêneros de princípio dialógico, razão porque decidimos compreendê-los como "divisão de vozes", já que o sujeito e o outro conhecem os seus espaços de enunciação, há cessão de falas e negociação das réplicas, ou seja, nesta divisão tanto o sujeito quanto o outro podem invadir o discurso do outro, o que é característico do gênero amplo, conhecido como "conversação espontânea" e "enunciados digitais", ainda pouco estudados. Há dois grupos de gêneros de princípio diálógico, aqueles de oralidade e escrita formais, palestras, conferências, aulas, sermões, para citar alguns da oralidade formal, e romances, teses de doutorado, ensaios, para citar alguns da escrita formal; nesses grupos se realizam réplicas de ações responsivas, nas quais há uma exigência ética e axiológica de respostas por parte dos outros, sejam leitores/ouvintes, ou outros sujeitos inscritos no discurso, assumido pelo sujeito autor, que entra em debate ou polêmica com os outros leitores, já inscritos ou previstos no contexto comunicativo discursivo. A réplica se realiza tematicamente, por completo, nesses dois últimos grupos, que direcionam a direção dos discursos comunicativos, em determinado contexto social. Não devemos nos esquecer, no entanto, que todo discurso, até mesmo os monovocais, dirige-se para o outro.

Gostaríamos de concluir esse subtópico com as seguintes palavras de Valentin Volóchinov:

Todo discurso é um discurso dialógico orientado para outra pessoa, para sua compreensão e resposta real ou possível. Essa orientação para o "outro", 
Volume 16 - Número 1 - jan/jul de 2021

para o ouvinte, pressupõe inevitavelmente a consideração da interrelação sócio-hierárquica que existe entre os interlocutores [...] Essa dependência do enunciado em relação ao peso sócio-hierárquico do auditório [constitui a] orientação social do enunciado. (VOLÓCHINOV, 2019, p. 280).

Os enunciados concretos existem no interior do princípio dialógico e exigem réplicas, outros enunciados concretos, em diferentes graus hierárquicos de poder, situação econômica, profissão e valores da subjetividade.

\section{As redes sociais digitais como ecossistemas comunicativos de réplicas a enunciados concretos}

O fenômeno das redes sociais digitais trouxe consigo um terreno fecundo para se observar a linguagem enquanto instância constituída pelo ideológico e pelo dialógico. No que toca ao ideológico, pelas práticas sociais via redes, é possível entender as filiações discursivas que acentuam o lugar histórico-social de quem enuncia, seja em postagens de conteúdos diversos, seja por respostas a essas postagens na forma de comentários on line. Em se tratando do dialógico, destacamos as relações de sentidos convocadas quando as interações discursivas são estabelecidas nas redes, funcionando, nesse contexto, como o exercício dialógico de compreender e de responder a enunciados concretos.

Sob essa ótica, é pertinente concebermos as redes sociais digitais como um ecossistema comunicativo de interações discursivas. Nelas, há o espaço para o diálogo, para o contraditório. Elas se fundamentam, então, na perspectiva de proporcionar à sociedade o convite ao engajamento, à participação, atraindo o pensamento de ato responsável e responsivo, tomando como referência a filosofia do ato encontrada em Bakhtin (2010, p. 7980 , itálicos do autor):

$\mathrm{O}$ ato - considerado não a partir de seu conteúdo, mas na sua própria realização - de algum modo conhece, de algum modo possui o existir unitário e singular da vida; orienta-se por ele e o considera em sua completude - seja no seu aspecto conteudístico, seja na sua real facticidade singular; do interior, o ato não vê somente o contexto único, mas também o único contexto concreto, o contexto último, com o qual relaciona tanto o seu sentido, assim como o seu fato, em que procura realizar responsavelmente a verdade única, seja do fato do sentido, na sua unidade concreta. Por isso é necessário, evidentemente, assumir o ato não como um fato contemplado ou teoricamente pensado do exterior, mas assumido do interior, na sua responsabilidade. [...] a responsabilidade do ato [...] a factualidade histórica e o tom emotivo-volitivo [...] ato responsável [...] é [...] a realização de uma decisão.

Como vemos, para Bakhtin (2010), o ato corresponde a realização do existir humano em eventos irrepetíveis de interações discursivas. Logo, o ato compromete o sujeito, no sentido de inseri-lo em processos de vivenciamentos que fazem os humanos implicarem-se no e pelo discurso. Por essa razão, o pensamento bakhtiniano define o ato não, unicamente, dentro de uma visão teorética. Todavia, imersa no ritmo da responsabilidade do envolvimento, na essência da expressão russa postupok, que significa, conforme Ponzio (2010), a compreensão de ato como "passo", como iniciativa, ação arriscada, isto é, como uma tomada de posição. 
Portanto, uma tomada de posição que torna as práticas de linguagem responsáveis e responsivas. Responsáveis na finalidade de engajar indivíduos em acordos de construções de sentidos nas mais variadas possibilidades de comunicação/interação social. Responsivas por, através desse engajamento, por exemplo, responsabilizar os interlocutores a produzirem respostas, a oportunizarem retornos de concordância ou não que se é enunciado e a trocarem conhecimentos.

Mergulhados nessa linha de raciocínio, lemos as redes sociais digitais: verdadeiros ecossistemas comunicativos de interações discursivas. $\mathrm{O}$ conceito de ecossistemas comunicativos advém de Martín-Barbero (2009) que entende os meios tecnológicos como possiblidades de aquisição do saber em um ambiente que recruta pessoas em situações de sociabilidades, como assim se encontram as redes sociais digitais. Já o conceito de interações discursivas, vinculamo-nos ao propagado pelo Círculo de Bakhtin. Para tanto, chamamos as palavras de Volóchinov (2017, p. 204-205, itálicos do autor) que afirma:

Efetivamente, o enunciado se forma entre dois indivíduos socialmente organizados, e, na ausência de um interlocutor real, ele é ocupado, por assim dizer, pela imagem do representante médio daquele grupo social ao qual o falante pertence. A palavra é orientada para o interlocutor, ou seja, é orientada para quem é esse interlocutor: se ele é integrante ou não do mesmo grupo social, se ele se encontra em uma posição superior ou inferior em relação ao interlocutor (em termos hierárquicos), se ele tem ou não laços sociais mais estreitos com o falante (pai, irmão, marido etc.).

Essa citação de Volóchinov (2017) enfoca uso social da linguagem. Segundo o estudioso, a reflexão sobre a natureza sociológica da língua reconhece o lugar da interação como centro de valores. Nessas condições, pensar em linguagem é pensar, necessariamente, na relação entre sujeitos que se engajam, que travam trocas conversacionais que, imprimem, por sua vez, processos de interação verbal. Isso implica dizer que a palavra, entendida como uma possibilidade de linguagem, é fruto de um sistema linguístico, mas que só atinge "sopro de vida" quando se considera a sua orientação social, a sua inclinação de um para outro(s), quando inserida entre falantes, entre sujeitos socialmente organizados e preenchidos por ideologias, por filiações histórico-sociais que situam tais sujeitos em correntes verboideológica de produção de sentidos dialogicamente marcados e demarcados.

Sob essas lentes, em síntese e em conformidade com Xavier e Almeida (2020), entendemos as redes sociais como interfaces tecnológicas que propiciam espaços de comunicação em sociedade, regradas por experiências interativas difusoras de discursos dialogicamente situados, funcionando, portanto, como um terreno oportuno para: 1) entreter uma vez que diverte usuários; 2) promover interações discursivas - pois oportuniza a percepção e a construção de pontos de vista, de valorações; 3) possibilitar investigações científicas - visto que abastece motivações de pesquisadores sobre a linguagem, a comunicação midiática, dentre outras áreas do conhecimento; e 4) colaborar como interfaces pedagógicas - auxiliando em contextos de ensino-aprendizagens de conteúdos disciplinares em diferentes níveis de formação, regular ou não, (da educação básica à pós-graduação).

Nessas condições e pautando-nos, principalmente, nos pontos 2) e 3) discorridos no parágrafo anterior, nesse artigo, ressaltamos a relevância de estudos científicos que tragam para o centro da discussão a circulação de enunciados concretos em redes sociais digitais, com o intuito de apresentarmos como, no âmbito da cultura digital, a sociedade em redes (CASTELLS, 2016) está, a todo momento, produzindo, fazendo circular e consumindo/recepcionando discursos dialogicamente situados nos mais variados campos da comunicação verboideológica. 


\section{Discussão metodológica}

A presente pesquisa vinculou-se à proposta de investigação netnográfica. Conforme Kozinets (2014), essa tipologia de pesquisa científica se caracteriza por analisar o comportamento de indivíduos e de grupos sociais na Internet, como também as dinâmicas desses grupos no ambiente on line e off line. Nesse contexto, tivemos como objeto de estudos os processos de interação discursiva ocorridos na rede social digital Twitter - "[...] microblogging que permite que os usuários enviem e leiam atualizações de outros contatos instantaneamente em textos de até 140 caracteres." (VICENTE, 2014, p. 135). Para tanto, consideramos as circunstâncias sociais de produção, de circulação e de recepção dos enunciados concretos em postagens e em comentários on line a partir das seguintes inquietações: quem enunciou?, quando, como e sob quais circunstâncias enunciou?, quais axiologias são possivelmente convocadas?, dentre outras.

Essas inquietações vão ao encontro do método dialógico de abordagem analítica sobre fatos de linguagens, tornando-os em fenômenos científicos na área de ciências humanas. $\mathrm{O}$ método dialógico pode ser entendido por meio do movimento analítico sobre a linguagem que considera, de forma indispensável: "1. Não separar a ideologia da realidade material do signo [...]; 2. Não dissociar o signo das formas concretas da comunicação social [...]; 3. Não dissociar a comunicação e suas formas de sua base material (infraestrutura)" (VOLÓCHINOV, 2017, p. 45). Nesse sentido, tendo os enunciados em circulação nas redes sociais e as leituras que seus membros realizaram como objetos de estudo, as discussões analíticas deste trabalho tiveram como fito principal compreender as axiologias difundidas pelas situações de interações discursivas nos recortes analisados.

Do ponto de vista do contexto comunicativo discursivo, elegemos como evento motivador, corpus deste artigo, ocorrido em 08/03/2021, em que o ministro do Supremo Tribunal Federal (STF), Edson Fachin, anulou as condenações ao ex-presidente Luiz Inácio Lula da Silva em relação à Operação Lava Jato, considerando, portanto, que a $13^{\text {a }}$ Vara Federal de Curitiba não tinha competência para julgar casos do triplex do Guarujá, do sítio de Atibaia e do Instituto Lula.

Com esse intuito, selecionamos a repercussão desse fato na rede social digital Twitter em duas postagens de pessoas públicas, bem como suas réplicas: o ex-ministro da Educação, Abraham Weintraub, e da deputada federal pelo Rio de Janeiro, Jandira Feghali. A seguir, apresentaremos a análise.

\section{Discussão analítica}

Partindo da concepção da linguagem como atividade dialógica e do enunciado como responsivo, compreendemos que este está sempre relacionado a algo e orientado a uma resposta ativa. É justamente essa dialogicidade da linguagem que licencia um diálogo de pontos de vista convergentes e dissonantes. Sendo assim, entendemos que, sob o ponto de vista axiológico, a linguagem está amalgamada de posicionamentos valorativos que, frente a um "projeto de dizer", traduz um índice de valorações apreciativas acerca daquilo que os sujeitos consideram sobre dados temas sociais, implicando, consideravelmente, a existência da construção de enunciados concretos regidos pela noção de "divisão de vozes", conforme apresentado na Tabela 1.

É nessa arena de diálogos que se encontram os discursos materializados na web, sobretudo os das redes sociais digitais, através dos quais os sujeitos protagonizam debates, expondo seus posicionamentos e valorações. Esses discursos, dentro de suas condições de 
Volume 16 - Número 1 - jan/jul de 2021

enunciabilidade, buscam circular como defesa ou repulsa a determinados temas políticos e ideológicos.

Dada a decisão judicial do ministro do STF, o ex-ministro da Educação, Abraham Weintraub, sempre ostensivo a Lula e à Esquerda política em seus discursos nas redes sociais, declarou em seu Twitter:

Figura 2: Postagem de Abraham Weintraub no Twitter

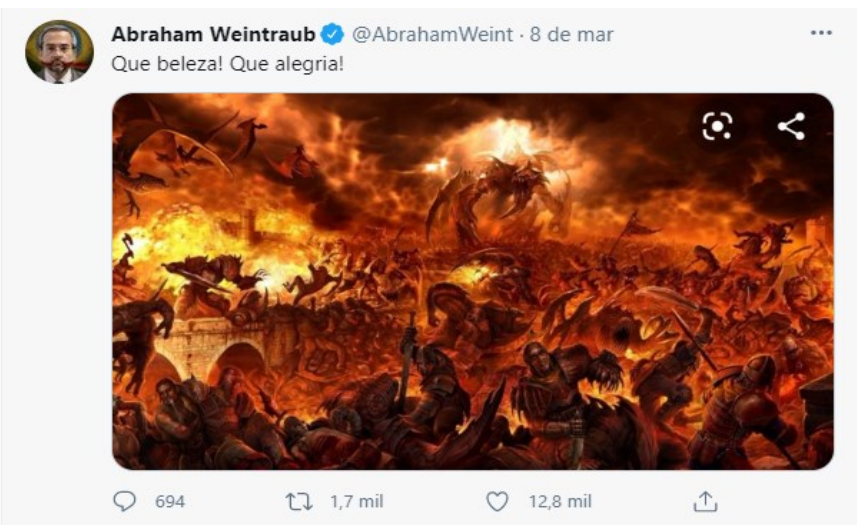

Fonte: https://twitter.com/AbrahamWeint/status/1369049833336668161?s=20. Acesso em 20/03/2021.

Inicialmente, consideramos que este enunciado de natureza verbo-visual conjuga em sua materialidade semiótica uma imagem fantasmagórica que, figurativamente, refere-se a um suposto inferno em que há fogo, animais e demônios em estado de tortura. Dentro da esfera do discurso religioso, sobretudo a que se filia o ex-ministro da Educação - o Protestantismo -, o hades (grego) é concebido como um lugar de aflição e de sofrimento, como o destino escatológico de condenação dos pecadores sem arrependimento. A escolha desta imagem cuja legenda é "Que beleza! Que alegria!" é intencional e parece sugestionar, em sua data de publicação, uma tonalidade valorativa quanto ao evento do julgamento que inocenta Lula. A legenda, por sua vez, investida de expressões exclamativas parece jogar ironicamente no seio social um tom de deboche em que se jogam duas vozes: a da alegria e a da dor; funcionando como um discurso às avessas, subvertendo os sentidos linguísticos do que verbalmente está posto. Ao entrelaçar o verbal ao não verbal, percebemos que os efeitos de sentido trazem uma nuance de que o inferno está em efervescência, em razão da decisão que mais parece ser uma imagem de: "Que horror! Que sofrimento!".

Os enunciados abaixo funcionam como réplicas a esse discurso, e cada uma constituise, ao seu modo, como um nó nessa teia do discurso. Nessa esteira discursiva, vejamos as publicações que estão em resposta a Weintraub: 
Figura 3: Réplicas à postagem de Abraham Weintraub no Twitter

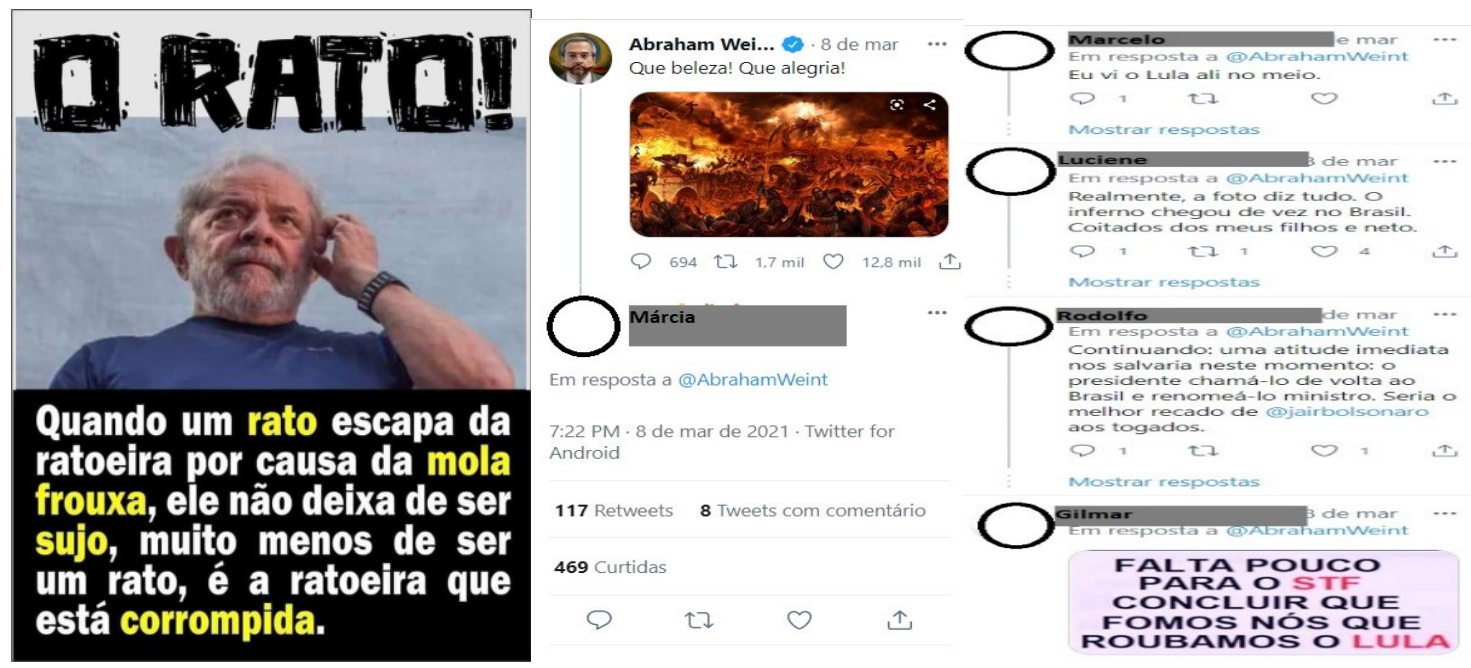

Fonte: https://twitter.com/AbrahamWeint/status/1369049833336668161?s=20. Acesso em 20/03/2021.

Como se faz perceber, todos os nomes assinalados nos comentários foram substituídos por nomes fictícios aleatórios. Nesse sentido, somente preservamos os nomes de figuras notada e reconhecidamente públicas. Em primeiro plano, destacamos que todos os retweets ao enunciado do ex-ministro funcionam como movimentos de réplica desses internautas, os quais compõem um misto de mensagens dialógicas que possuem comentários polêmicos que são de natureza verbal e visual.

Por seu turno, a resposta de Márcia, materializada em um meme ${ }^{4}$, chama-nos atenção pelo fato de que foi o enunciado concreto o fato motivador capaz de gerar aceitabilidade e uma responsividade ativa. Nesse caso, o discurso concreto, que se filia ao contexto extra verbal da enunciação, não mantém, linguisticamente, nenhuma marca materializável referente a Lula; mesmo assim, a inscrição discursiva do Weintraub no Twitter gera em Márcia uma ressonância de réplica valorativa, funcionando como uma resposta à intenção do que o outro pretendia.

Do ponto de vista axiológico, as escolhas linguísticas desse meme sinalizam uma intenção marcada por acentos linguísticos valorativos que se revelam no plano da nominalização, e isso pode ser evidenciado pelos termos grifados em amarelo "rato", "mola frouxa", "sujo" e "corrompida". Observe-se o processo de nomeação com palavras que traduzem insultos e um revestimento de violência verbal ao afirmar que o ex-presidente Lula é "O RATO!". Consiste-se, assim, a tomada de posição que, no jogo de linguagem de Márcia, reforça o argumento de que, aqui, "O RATO!" e "sujo" podem ser lidos como ladrão e corrupto. Nesse embaralhamento de vocábulos, é o aspecto extra verbal que nos autoriza uma compreensão de índices de valores negativos que colocam à prova a imparcialidade da Justiça. Como se lê, a atribuição dos termos "mola frouxa" e "ratoeira corrompida" denota uma entoação avaliativa depreciativa acerca da decisão do ministro do STF, reforçando o fato de que o "rato" só foi inocentado em razão de o STF ser, sob esse horizonte do enunciador, uma espécie de "mola frouxa", objeto de quem (faz) "escapa"(r) o ex-presidente.

Essa desqualificação orientada ao STF traz à tona um discurso já dito pelo Weintraub que, em reunião com outros ministros do Presidente Jair Bolsonaro, no dia 22 de abril de

\footnotetext{
${ }^{4}$ Conforme Melo (2018), concebemos aqui meme como um gênero discursivo, já que nele se abriga uma rede complexa de enunciados vivos, históricos e ideológicos. Eles são amalgamados de enunciados concretos e constituídos pelas linguagens verbal e não verbal; para além disso, contém um conteúdo irônico e são replicadores de informações no seio social.
} 
Volume 16 - Número 1 - jan/jul de 2021

2020, como reportado nas mídias, preconizava a ideia de que os ministros do STF eram "vagabundos" e, por essa razão, deveriam ser presos. Esse fio discursivo parece ser retomado tanto no comentário de Márcia, quanto no de Gilmar. Este último, por sua vez, reflete e refrata um posicionamento axiológico nocivo e sarcástico quanto à postura do STF na referida decisão, o que corrobora a leitura de que "Falta pouco para", sugestionando uma arbitrariedade intencional dessa instância jurídica, a de que a sociedade em geral está à mercê de ser imputada pelo crime de que o enunciador, asseguradamente, atribui a Lula. Tal entoação reforça, desse modo, o ponto de vista argumentativo do enunciado concreto.

Nessa ordem de avaliações e de respostas dos enunciadores envolvidos, tal como assinala Rodolfo, em sua réplica, há uma confrontação direta com os "togados", referindo-se aos membros do STF, como se estes estivessem subordinados "ao melhor recado" do mencionado@jairbolsonaro. Esse discurso é tomado como uma "atividade ativa" e como um dado tom responsivo que aponta para uma suposta salvação: "o presidente chamá-lo de volta ao Brasil e renomeá-lo ministro". Nesse acarretamento, é possível inferir que os ministros do STF estariam sendo amedrontados por uma possível decisão de o Presidente Bolsonaro reintegrar o Weintraub à sua equipe e, assim sendo, esta seria "uma atitude imediata" de salvação frente a essas decisões do Supremo, reforçando ainda mais um clima de insegurança democrática, de instabilidade política e de desrespeito aos ministros da Suprema Corte.

Retornando à imagem do inferno, o enunciador Marcelo declara: "Eu vi o Lula ali no meio", referindo-se ao meio das chamas, como se o ex-presidente se assemelhasse a um "demônio", como se fosse uma imagem fantasmagórica que causasse medo e terror, voz presidida na primeira enunciação de Weintraub. Luciene, em seguida, reacentua a valoração tanto de Marcelo quanto do Weintraub, ao declarar que "Realmente, a foto diz tudo. O inferno chegou de vez no Brasil. Coitados dos meus filhos e neto". Essas relações dialógicas entre esses enunciadores deflagram índice de valor político e estão saturadas ideologicamente de uma agressão à face de Lula e aos poderes do STF. Nesse caso, a escolha lexical do adjunto adverbial "realmente", na posição tópica oracional, contribui para sustentar a ideia de afirmação, de tom asseverativo de todo o conteúdo que se declara. Ainda nessa leitura, "inferno" e "Brasil" podem ser tomados como vocábulos equivalentes semanticamente, uma vez que, diante do fator contextual e desses pontos de vista, a não condenação de Lula implicou um cenário de devastação total, de quem o sujeito enunciador quer livrar seus filhos e neto.

Partindo da ideia de que todo enunciado concreto não permite o uso da palavra neutra, a posição política do enunciador - ato real e concreto na enunciação - ensejará no signo linguístico (na palavra) um certo acento valorativo prenhe de constatação, de contradição, de confirmação, de negação e até de confrontação, acionando forças centrípetas e centrífugas no jogo argumentativo da linguagem. É isso o que também se observa no outro polo político e ideológico.

A seguir, trataremos da mensagem do Twitter publicada pela médica e deputada federal Jandira Feghali (PCdoB/RJ), no mesmo dia da publicação da sentença de Fachin. 
Volume 16 - Número 1 - jan/jul de 2021

Figura 4: Postagem de Jandira Feghali no Twitter

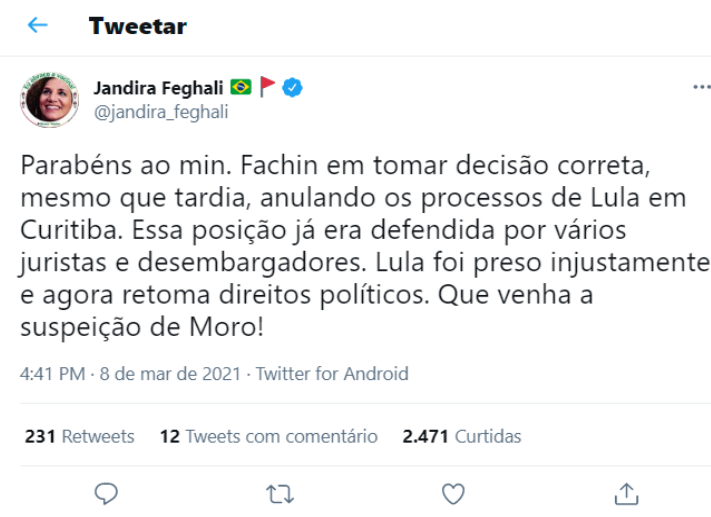

Fonte: https://twitter.com/jandira feghali/status/1369010500282036225?s=20. Acesso em 20/03/2021.

Como se lê, em tom de celebração e de parabéns, a deputada festeja a decisão tomada pelo ministro Fachin, tipificando-a, ainda que por meio de uma relação de sentido de concessividade - "mesmo que tardia" -, como a "decisão correta" o fato de haver a anulação dos "processos de Lula em Curitiba". Ressalta, ainda, que essa decisão é a mais coerente, uma vez que já era consensual entre várias autoridades da Justiça, como assinala em "vários juristas e desembargadores". A escolha lexical do advérbio "injustamente" corrobora a interpretação de que o ex-presidente Lula foi acusado de forma infundada e inaceitável, sendo vítima das acusações de quem ela espera "suspeição" do caso, do juiz Sérgio Moro. Esse fio condutor do discurso de Jandira é dialógico e encontra ressonâncias em outras mídias, as quais apresentam, também, de forma resumida, os "EMBARGOS DECLARATÓRIOS NO HABEAS CORPUS 193.726 PARANÁ", cuja alegação é a de que a $13^{\text {a }}$ Vara Federal de Curitiba, em que estava o ministro Moro, não tinha competência para julgar os casos envolvendo o expresidente Lula.

Essa nulidade dos outros atos decisórios sobre Lula é comemorada também por Jéssica e por Marcos. Vejamos:

Figura 5: Réplicas à postagem de Jandira Feghali no Twitter

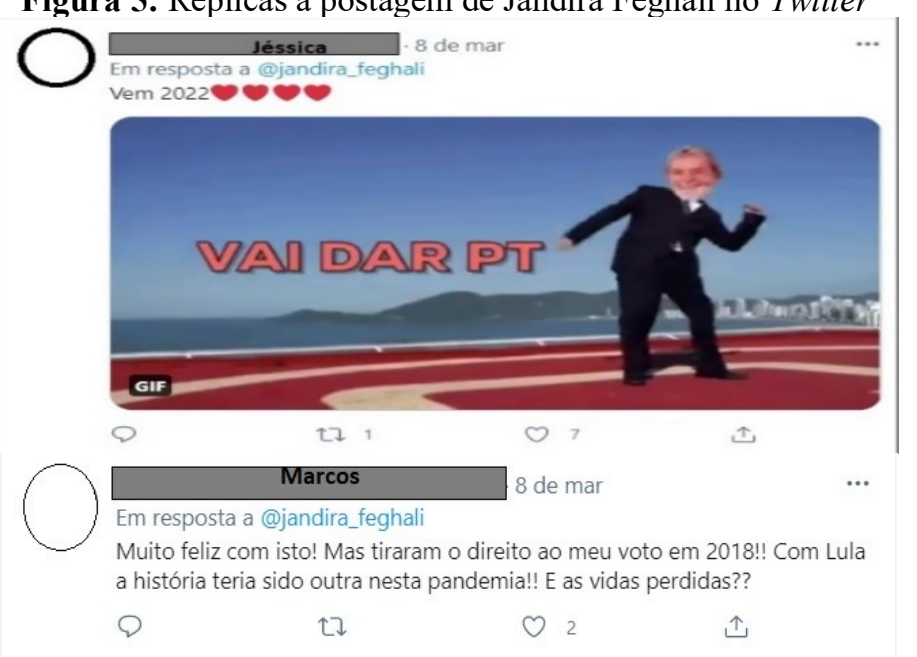

Fonte: https://twitter.com/jandira feghali/status/1369010500282036225?s=20. Acesso em 20/03/2021. 
Esses dois internautas, em congruência com a argumentação materializada pela deputada, fazem coro com suas réplicas ativas, fortalecendo e confirmando o que foi verbalmente posto anteriormente.

Pelo contexto extra verbal, Jéssica, por sua vez, ao escrever: "Vem 2022 Q $\bigcirc$ O O" na legenda desse GIF $^{5}$, compreende, de forma responsiva e ativa, que a decisão do STF torna Lula elegível na próxima votação presidencial que ocorrerá no próximo ano. Nesse aspecto emotivo-volitivo, os emojis de corações traduzem um misto de amor e de esperança em referência ao que ela mesma projeta para o ano vindouro - recurso típico presente na linguagem de "enunciados digitais", como sinalizamos na Tabela 01. As partes da verbovisualidade do GIF, que mesclam à sentença "VAI DAR PT" a imagem do ex-presidente Lula, como se estivesse dançando e comemorando a sua vitória, são prenhes de tonalidades intrinsecamente valorativas, as quais direcionam uma interpretação quanto ao retorno de Lula e do PT ao Governo Geral da nação brasileira.

Marcos também enfatiza essa compreensão, marcando-se através de um jogo de valorações em conflito, pois ao passo que, em resposta à deputada, declara-se "muito feliz com isto!", promove algumas indagações que são insatisfações. Ao construir seu discurso investido de posicionamentos políticos, ele lança mão de questões mais polêmicas: (1) como a perda de seu voto em 2018 e (2) o número elevado de mortes pela Covid-19. Em sua compreensão, Marcos declara que "Com Lula a história teria sido outra nesta pandemia!!". Esse índice de valor que o sujeito atribui a Lula parece resgatar dialogicamente o fato de que, por exemplo, em meio à pandemia do vírus H1N1, entre 2009 e 2010, as ações estratégicas de vacinação foram mais produtivas se comparadas com as de atualmente, totalizando, à época, mais de 80 milhões de vacinados em apenas três meses, conforme amplamente divulgado na mídia nacional televisiva.

Nesse momento, apresentamos a Figura 06 que ainda apresenta réplicas à postagem da deputada Jandira Feghali.

Figura 6: Ainda sobre réplicas à postagem de Jandira Feghali no Twitter

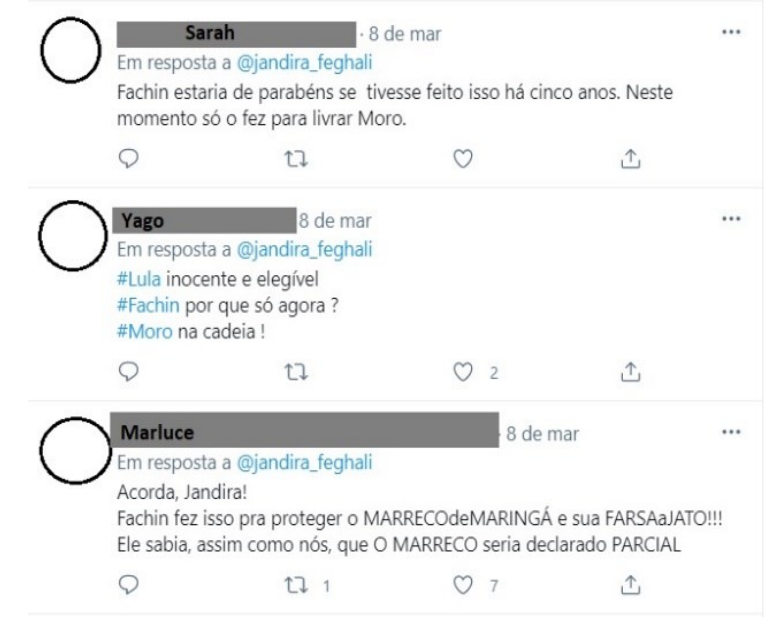

Fonte: https://twitter.com/jandira_feghali/status/1369010500282036225?s=20. Acesso em 20/03/2021.

Sarah, em tom de contestação à Jandira, recorre às formas linguísticas, por meio da correlação verbal que marca a condicionalidade - "estaria" e "se tivesse" - como uma moldura de referência para construção de sua hipótese e de sua afirmação: a decisão de Fachin

\footnotetext{
${ }^{5}$ O GIF (Graphics Interchange Format) é um formato de imagem, sem áudio, de compactação de várias cenas que expressam uma sequência de movimentos, transmitindo sempre uma mensagem.
} 
Volume 16 - Número 1 - jan/jul de 2021

deveria ter ocorrido "há cinco anos" e, portanto, esta não é merecedora dos parabéns. Em sua entoação valorativa, a internauta deixa compreender que a decisão do ministro do STF visava apenas livrar Moro da suspeição do caso, e não especificamente, Lula. Esse revestimento linguístico e contextual é sinalizador de que, para esse sujeito, o STF é parcial e está aparelhado para defender seus interesses pessoais.

Nas escolhas lexicais de Yago, encontramos uma gradação estabelecida por meio de um acarretamento lógico que compreende três sujeitos diferentes: Lula, Fachin e Moro. Em réplica dialogal e valorativa ao termo "decisão tardia", esse internauta corrobora não só a interpretação de Sarah, mas também a de Jandira. Linguisticamente, suas sentenças interrogativa e exclamativa, ao passo que questionam "\#Fachin por que só agora?", impõe no social uma irrupção de um novo sentido: a prisão de Moro, vista em “\#Moro na cadeia!".

Marluce, no entanto, ao mobilizar uma sequência linguística injuntiva, por meio de vocativo e de verbo imperativo - "Acorda, Jandira!", interpela, por meio da confrontação verbal, a deputada quanto à ingenuidade de seu agradecimento ao ministro Fachin. O processo de entoação axiológica encontrado na réplica desse sujeito está, arquitetonicamente, marcado na nomeação que ela atribui: "MARRECOdeMARINGÁ" e "FARSAaJATO". Como se vê, essas nomeações tipificam não só, irônica e negativamente, o juiz Sérgio Moro, mas também a operação Lava Jato. O termo "FARSA", por exemplo, licencia uma leitura de que todo processo de acusação a Lula foi promovido por mentiras e por uma intencionalidade de Moro. No campo de respostas valorativas, Marluce deixa escapar que Fachin só tomou tal decisão para "proteger" o outro juiz, pois, segundo ela, o STF sabia, "assim como nós", que o juiz "seria declarado PARCIAL". Em suma, toda valoração empreendida por Marluce pode ser, esquematicamente, assim descrita: confrontação, seguida de nomeações e acusação.

\section{Considerações finais}

A análise empreendida neste artigo mostrou o quanto as redes sociais digitais, especialmente o Twitter, propiciam espaços de interações discursivas. Os recortes selecionados possibilitaram apresentar a produtividade do Twitter em hospedar postagens veiculadoras de discursos que vão ao encontro do lugar social ocupado pelos usuários da rede: no caso de Abraham Weintraub, a valoração negativa à atitude do ministro do STF, Edson Fachin, quando da anulação das condenações a Lula; no inverso da valoração de Weintraub, uma outra enunciada pela deputada federal Jandira Feghali que "aplaude" a decisão de Fachin. Duas valorações, dois pontos de vista que transitam na rede e que permitem o surgimento de réplicas.

E é pensando em réplicas que destacamos os comentários on line analisados como resultado do poder de convite à participação social emitida pelas interações contemporâneas em rede. Tais comentários, assim como as postagens, acentuam, com veemência, modos de dizer, modos de perceber o enunciado do outro e, consequentemente, modos de construir os seus próprios enunciados, concretos por excelência. Dessa forma, constatamos que os enunciados digitais operam em "divisões de vozes" que criam expectativas de respostas negociadas.

Em suma, lemos que uma investigação dessa natureza oportuniza fomentar o trato científico, em humanidades, que põe em relevo a dinâmica das interações discursivas em contextos de cultura digital, como, dessa maneira, se inserem as redes sociais: ecossistemas comunicativos que aguçam a circulação de discursos vários, reforçando a perspectiva do Círculo de Bakhtin que apregoa a necessidade de que a palavra e outras linguagens querem 
Volume 16 - Número 1 - jan/jul de 2021

sempre ser ouvidas e, além desse movimento, querem sempre ser respondidas em um exercício dialógico de compreensões e de respostas a enunciados concretos.

\section{Referências}

BAKHTIN, M. Os gêneros do discurso. São Paulo: 34, 2016.

BAKHTIN, M. Para uma filosofia do ato responsável. 2. ed. Tradução de Valdemir Miotello e Carlos Alberto Faraco. São Carlos: Pedro \& João, 2010.

CASTELlS, M. A sociedade em rede. Tradução de Roneide Venancio Majer. 17. ed. São Paulo: Paz e Terra, 2016.

KOZINETS, R. V. Netnografia: realizando pesquisa etnográfica online. Porto Alegre: Penso, 2014.

MARTÍN-BARBERO, J. Dos meios às mediações: comunicação, cultura e hegemonia. 6. ed. Tradução de Ronald Polito e Sérgio Alcides. Rio de Janeiro: EDUFRJ, 2009.

MELO, R. M. A valoração em memes: um estudo dialógico no campo da comunicação do discurso. Dissertação de Mestrado apresentada ao Programa de Pós-Graduação em Linguística. Universidade Federal da Paraíba. João Pessoa, 2018.

PERINI, M. A. Gramática do português brasileiro. São Paulo: Parábola, 2010.

PONZIO, A. A concepção bakhtiniana do ato como dar um passo. In.: BAKHTIN, M. M. Para uma filosofia do ato responsável. 2. ed. Tradução de Valdemir Miotello e Carlos Alberto Faraco. São Carlos: Pedro \& João, 2010, p. 09-38.

SOUZA, G. T. Introdução à teoria do enunciado concreto. São Paulo: FFLCH/USO, 2002.

VICENTE, E. M. Redes sociais: ciberespaço - novas formas de interação das redes sociais. Santa Cruz do Rio Pardo: Viena, 2014.

VOLÓCHINOV, V. A palavra na vida e a palavra na poesia: ensaios, artigos, resenhas e poemas. Organização, tradução, ensaio introdutório e notas de Sheila Grillo e Ekaterina Vólkova Américo. São Paulo: 34, 2019.

VOLÓCHINOV, V. Marxismo e filosofia da linguagem: problemas fundamentais do método sociológico na ciência da linguagem. Tradução, notas e glossário de Sheila Grillo e Ekaterina Vólkova Américo. São Paulo: 34, 2017.

XAVIER, M. M.; ALMEIDA, M. F. Redes sociais, linguagem e interação discursiva. In.: XAVIER, M. M. (Org.). Linguística Contemporânea: estudos sobre discursos, cultura digital e ensino. São Paulo: Mentes Abertas, 2020, p. 183-197. 